\title{
A comparative study of perioperative and survival outcomes of robot-assisted radical cystectomy in patients over 80 and under 80 years old
}

Shangxun Xie ${ }^{\dagger}$, Zihan Zhao ${ }^{\dagger}$, Baofu Feng, Shiwei Zhang, Gutian Zhang, Xiaogong Li, Hongqian Guo* and Rong Yang ${ }^{*}$

\begin{abstract}
Background: Radical cystectomy (RC) is the standard treatment for bladder cancer, but the safety and efficacy of this treatment for elderly people need to be considered. We compare perioperative data and survival outcomes between elderly ( $\geq 80$ years) and younger ( $<80$ years) patients undergoing robot-assisted radical cystectomy (RARC).

Methods: We reviewed demographic, perioperative clinical and follow-up data of 190 consecutive patients with urothelial carcinoma of bladder who received RARC from May 2015 to December 2018 in Nanjing Drum Tower Hospital. The patients were divided into 2 groups by age: $\geq 80$ years and $<80$ years. Perioperative outcomes were compared between 2 groups. Logistic regression method was used to analyze the factors that may affect preoperative complications. Cox regression model was employed to analyze the factors affecting 3-year overall survival (OS), recurrence-free survival (RFS), and cancer-specific survival (CSS).

Results: Of the 190 patients, 44 (23.2\%) were octogenarians. The elderly patients did not statistically differ from younger patients in most of the demographic, perioperative, and pathological information. American Society of Anesthesiologists (ASA) score ( $p=0.045)$ and Charlson comorbidity index (CCI) $(p=0.035)$ could predict high-grade and any grade complications, respectively. Positive lymph node and $\mathrm{pT} \geq 3$ were main factors affecting OS, RFS, and CSS. ASA score $(p=0.048)$ and CCI $(p=0.003)$ could predict OS and RFS, respectively. Elderly group had worse OS ( $p=$ $0.007)$ and CSS ( $p=0.027)$ but similar RFS ( $p=0.147)$ compared with younger group.

Conclusion: The elderly who received RARC had similar risk of perioperative complications and RFS compared with younger patients. RARC could be an alternative treatment for selected octogenarians.
\end{abstract}

Keywords: Robotic surgical procedures, Radical cystectomy, Bladder cancer, Octogenarians

\footnotetext{
*Correspondence: dr.ghq@163.com; doctoryr@gmail.com

${ }^{\dagger}$ Shangxun Xie and Zihan Zhao contributed equally to this work.

Department of Urology, Nanjing Drum Tower Hospital, The Affiliated Hospital of Nanjing University Medical School, Institute of Urology, Nanjing University,

321 Zhongshan Road, Nanjing 210008, Jiangsu, China
}

(C) The Author(s). 2021 Open Access This article is licensed under a Creative Commons Attribution 4.0 International License, which permits use, sharing, adaptation, distribution and reproduction in any medium or format, as long as you give appropriate credit to the original author(s) and the source, provide a link to the Creative Commons licence, and indicate if changes were made. The images or other third party material in this article are included in the article's Creative Commons licence, unless indicated otherwise in a credit line to the material. If material is not included in the article's Creative Commons licence and your intended use is not permitted by statutory regulation or exceeds the permitted use, you will need to obtain permission directly from the copyright holder. To view a copy of this licence, visit http://creativecommons.org/licenses/by/4.0/ The Creative Commons Public Domain Dedication waiver (http://creativecommons.org/publicdomain/zero/1.0/) applies to the data made available in this article, unless otherwise stated in a credit line to the data. 


\section{Introduction}

Bladder cancer (BCa) is the second most common urinary tract malignancy. In 2018, there were 549, 393 new cases and 199, 922 deaths of bladder cancer around the world [1]. The incidence of bladder cancer increases with age, and about $46 \%$ of patients diagnosed with bladder cancer from 2013 to 2017 in the USA were 80 years or older [2]. With the aggravating trend of aging population throughout the world, we could predict that the number of elderly patients with bladder cancer will be further increasing in the future.

The NCCN Guidelines divide treatment recommendations for urothelial carcinoma of the bladder according to non-muscle invasive disease (NMIBC, including $\mathrm{Ta}$, $\mathrm{T} 1$, and Tis) and muscle-invasive disease (MIBC, $\geq \mathrm{T} 2$ disease) [3]. The treatment of NMIBC mainly consists of transurethral resection of bladder tumor (TURBT) and postoperative intravesical treatment [4]. Radical cystectomy (RC) and pelvic lymph node dissection is the standard of care for the treatment of localized MIBC and high-risk NMIBC [3]. However, not all patients are suitable for $\mathrm{RC}$ due to the high morbidity rate, with age being a key consideration on whether to pursue radical surgical management. Although current guidelines for treatment of MIBC do not exclude the possibility of RC for old patients, they suggest that life expectancy should still be taken into account [5]. More minimally invasive approaches and modified techniques are underscored to reduce the surgical risk of $\mathrm{RC}$ [6]. In recent years, laparoscopic and robotic-assisted laparoscopic surgeries have been more and more applied to the treatment of bladder cancer [7]. These minimally invasive methods may promote postoperative recovery and reduce the incidence of perioperative complications without sacrificing oncologic outcome [8]. Tang's meta-analysis has shown that laparoscopic RC could provide benefits to the patients in terms of decreased blood loss, shorter hospital stays, and less postoperative complications compared with open $\mathrm{RC}$, but it was with longer operation time [9]. Additionally, laparoscopic RC has a long learning curve and requires high technical level of the operator, so robot surgery emerges as the times require.

Robot-assisted radical cystectomy (RARC) has been proved to have great advantages in decreased intraoperative blood loss, decreased blood transfusion rate, and shorter hospital stay compared with other approaches $[10,11]$. In addition, RARC improves the visualization and ergonomics of surgery for urologists [12, 13]. Nevertheless, the data about the outcomes of RARC in octogenarians is limited. It is still controversial whether it is safe and feasible for the elderly over 80 years old to receive RARC according to previous researches [14, 15].

In view of this, the aim of our study is to report the perioperative and short-term oncological outcomes of
RARC in elderly $\mathrm{BCa}$ patients, and to compare these data with the outcomes observed in younger patients.

\section{Methods}

\section{Clinical data}

From May 2015 to December 2018, a total of 203 consecutive patients underwent RARC at Nanjing Drum Tower Hospital. Main indications for RARC were primary muscle-invasive transitional cell carcinoma $(n=73$, $38.4 \%)$ or high-risk non muscle-invasive bladder cancer (CIS, refractory pTa-1, or BCG-unresponsive) $(\mathrm{n}=117$, 61.6\%). All the operations were performed by Professor Hongqian Guo. Patients with missing information or lack of follow-up were excluded $(n=13)$. Therefore, 190 patients were reviewed and divided into 2 groups according to the age, those who were 80 years old or older $(\mathrm{n}=44)$, and those below $80(\mathrm{n}=146)$, for comparison. The present study was approved by the Ethics Committee of Nanjing Drum Tower Hospital in accordance with the Declaration of Helsinki.

All pathological specimens were examined by the experienced pathologists of Nanjing Drum Tower Hospital. The tumor grade and classification was in accordance with 2016 WHO (World Health Organization) classification standard [16]. The pathological staging was in accordance with 8th edition TNM staging method of American Joint Committee on cancer (AJCC) in 2017 [17]. All 90-day postoperative complications were defined and recorded on the basic of an established five grades of the Clavien-Dindo system. Minor complications were classified as grades 1 and 2, while major complications were classified as grades 3,4 , and 5 [18].

\section{Surgery}

All patients received RARC and urinary diversion with or without pelvic lymphadenectomy by da-Vinci Si (Intuitive Surgical, Sunnydale, CA) robot. And patients received three different options for urinary diversion, including ileal conduit, orthotopic neobladder, or ureterostomy. The choices for urinary diversion and lymphadenectomy were mainly made according to the physical conditions and personal willingness of patients before the operation.

\section{Follow-up}

The patients were followed up every 3 months for the first year, every 6 months for the second year, and once a year thereafter. Follow-up included physical examination, blood routine examination, liver and kidney function, electrolyte, chest CT, and contrast-enhanced CT examination of urinary system (according to the patient's renal function). 


\section{Statistical analysis}

The Mann-Whitney test was used to assess differences in continuous variable between two groups. Differences in categorical variables between the two groups were assessed with chi-square test. Recurrence-free survival (RFS) was defined as time from date of RARC to local recurrence or distant metastasis, based on pathological or radiologic evidence. Overall survival (OS) was defined as time from date of RARC to death due to any reasons. Cancer-specific survival (CSS) was defined as time from date of RARC to death due to bladder cancer. Factors that may affect the prognosis of RARC (age, sex, lymph node dissection, American Society of Anesthesiologists (ASA) score, Charlson comorbidity index (CCI), T stage, lymph node metastasis) were included in Cox multivariate risk proportion model was used to analyze their impact on OS, RFS, and CSS. Univariable and multivariable logistic regression models were used to analyze the association of complications with risk factors of interest and assessed the impact of age ( $\geq 80 \mathrm{vs}<80)$ on the risk of intraoperative blood loss, length of stay, and high-grade and any grade complications. The sample size of logical regression analysis uses the method of EPV (events per variable), and it is generally recommended that EPV be at least 10 [19]. In this study, there are 8 covariates of logical regression, and 149 samples are needed by calculating the sample size according to EPV, so the number of people included in logical regression $(n=190)$ is sufficient. All logistic regression data were summarized by odds ratio (OR) with $95 \%$ confidence intervals (CIs). All Cox regression data were summarized by hazard ratios (HR) with 95\% CIs. The values of $p<0.05$ were regarded as statistical significance. Because the predictive nature of each factor in the presence of other factors was of interest, all variables were included in the multivariable analysis without considering the univariable results. The distributions of OS, RFS, and CSS stratified by age $(\geq 80$ vs $<80$ ) were described using Kaplan-Meier curve and compared using log-rank test. All analyses were performed with the SPSS version 25.0 (IBM Corp.).

\section{Results}

\section{Patient and perioperative characteristics}

The series included 146 patients $<80$ years and 44 patients $\geq 80$ years (Table 1 ). The preoperative parameters (sex, BMI, ASA score, CCI) were similar in younger and elderly groups. The main comorbidities in the elderly group were hypertension $(n=29,65.9 \%)$, diabetes mellitus $(n=9,20.5 \%)$, chronic obstructive pulmonary disease $(\mathrm{n}=7,15.9 \%)$, coronary heart disease $(\mathrm{n}=5,11.4 \%)$, and chronic kidney disease $(n=5,11.4 \%)$. The main comorbidities in the younger group were hypertension $(n=57$, $39.0 \%)$, diabetes mellitus $(\mathrm{n}=21,14.4 \%)$, coronary heart disease $(\mathrm{n}=8,5.5 \%)$, chronic obstructive pulmonary disease $(n=5,3.4 \%)$, and ulcer disease $(n=3,2.1 \%)$. In terms of perioperative outcomes, mean operating time was significantly shorter in octogenarians $(p<0.001)$. Transfusions were more commonly given to elderly group ( $p=0.015)$, while the pelvic lymph node dissection (PLND) were performed less in this group $(p=0.019)$. In addition, no differences were noted between groups in respect of urinary diversion, pathological results, length of stay, complications at all grades, and 90-day postoperative mortality.

\section{Complication and survival analyses}

The incidence of 90-day postoperative any-grade complications was $50.0 \%$ in the elderly group and $54.8 \%$ in the younger group. The most common any-grade complications in both groups were postoperative ileus and urinary tract infection, but the proportion was slightly different. The proportion of intestinal obstruction and urinary tract infection in the elderly group were 13.6\% and $11.4 \%$, respectively, and the younger group were $11.0 \%$ and $13.0 \%$. The incidence of high-grade complications in the two groups was $9.1 \%$ and $6.2 \%$, respectively. The high-grade complications in the elderly group included intestinal obstruction requiring surgical intervention $(\mathrm{n}=2,4.5 \%)$ and pulmonary embolism $(\mathrm{n}=2,4.5 \%)$. The high-grade complications in the younger group included intestinal obstruction requiring surgical intervention $(n=4,2.7 \%)$, septic shock $(n=3,2.1 \%)$, incisional hernia $(n=1,0.7 \%)$, and hydronephrosis $(n=1,0.7 \%)$. The re-operation rate in the elderly group and younger group were $4.5 \%$ and $4.1 \%$, respectively. The re-operation in the elderly group was caused by intestinal obstruction, while the re-operations in the younger group were due to intestinal obstruction, incisional hernia, and hydronephrosis. The logistic regression analysis of complications showed that ASA score $(\mathrm{OR}=4.662 ; p=0.045)$ could independently predict occurrence of high-grade complications and CCI (OR=1.608; $p=0.035)$ was significant predictor of any-grade complications, but other variables were not independent predictors (Table 2). Meanwhile, we also inspected the impact of age on the risk of increased blood loss, transfusion, prolonged hospitalization, and major and any grade complications (Table 3). The risk of above factors were not increased in the octogenarians.

Median follow-up time of all patients was 29.1 months (range from 7 to 58 months). Kaplan-Meier curves showed that 3 -year RFS were $72.3 \%$ and $54.4 \%$ in younger and elderly groups $(p=0.147)$, respectively. In addition, 3-year CSS and OS of octogenarians was also significantly lower than that of younger group (Fig. 1). In Cox multivariable regression analyses (Table 4), CCI $(\mathrm{HR}=1.812 ; p=0.003)$, tumor stage $\mathrm{pT} \geq 3 \quad(\mathrm{HR}=3.206 ; p<$ $0.001)$, and positive lymph node status $(\mathrm{pN}(+))(\mathrm{HR}=$ 
Table 1 Demographic, perioperative and pathological characteristics of 190 patients treated with robot-assisted radical cystectomy (RARC)

\begin{tabular}{|c|c|c|c|}
\hline & Elderly group $(\geqq 80, n=44)$ & Younger group $(<80, n=146)$ & p-value \\
\hline Age, median (range) & $83(80-92)$ & $65(41-79)$ & $<0.001$ \\
\hline Sex (male to female) & $37: 7$ & $130: 16$ & 0.378 \\
\hline BMI median (range) & $22.9(15.4-30.4)$ & $23.5(16.5-35.5)$ & 0.083 \\
\hline ASA score $(1 / 2 / 3)$ & $12 / 5 / 27$ & $46 / 33 / 67$ & 0.137 \\
\hline CCl class $(0 / 1 / 2 / 3)$ & $9 / 19 / 11 / 5$ & $32 / 72 / 40 / 2$ & 0.053 \\
\hline $\mathrm{Hb}, \mathrm{g} / \mathrm{L}$ median (range) & $119(63-157)$ & $126(53-169)$ & 0.015 \\
\hline Alb, g/L median (range) & $36.9(31.3-59.3)$ & $37.6(24.4-47.3)$ & 0.146 \\
\hline Operating time, min median (range) & $308(160-480)$ & $399(235-670)$ & $<0.001$ \\
\hline EBL, ml median(range) & $300(100-1400)$ & $406(100-1900)$ & 0.475 \\
\hline Transfusion, n (\%) & $21(47.7)$ & $41(28.1)$ & 0.015 \\
\hline PLND, n (\%) & $33(75.0)$ & $130(89.0)$ & 0.019 \\
\hline Number of lymph node, $\mathrm{n}$ median (range) & $13(1-29)$ & $15(1-39)$ & 0.274 \\
\hline Urinary diversion, $\mathrm{n}(\%)$ & & & 0.051 \\
\hline Ileal conduit & $25(56.8)$ & $95(65.1)$ & \\
\hline lleal neobladder & $0(0)$ & $10(6.8)$ & \\
\hline Ureterostomy & $19(43.2)$ & $41(28.1)$ & \\
\hline cT (cT2 over) n, (\%) & $21(47.7)$ & $52(35.6)$ & 0.148 \\
\hline CT (Tis/a/1/2/3/4) & $0 / 2 / 8 / 13 / 13 / 8$ & $7 / 7 / 44 / 36 / 40 / 12$ & 0.201 \\
\hline $\mathrm{cN}(+) \mathrm{n},(\%)$ & $6(13.6)$ & $36(24.7)$ & 0.122 \\
\hline $\operatorname{LVI}(+) \mathrm{n},(\%)$ & $17(38.6)$ & $54(35.5)$ & 0.843 \\
\hline Positive surgical margin, n (\%) & $2(4.5)$ & $6(4.1)$ & 1.000 \\
\hline Postoperative hospital stay, days median (range) & $12(7-29)$ & $15(6-39)$ & 0.437 \\
\hline Complications according to Clavien-Dindo, n (\%) & & & 0.605 \\
\hline 0 & $22(50.0)$ & $66(45.2)$ & \\
\hline $1-2$ & $18(40.9)$ & $71(48.6)$ & \\
\hline $3-5$ & $4(9.1)$ & $9(6.2)$ & \\
\hline 90-day mortality, n (\%) & $3(6.8)$ & $3(2.1)$ & 0.275 \\
\hline
\end{tabular}

$B M I$ body mass index, ASA American Society of Anesthesiologists, CCl Charlson comorbidity index, Hb hemoglobin, Alb albumin, EBL estimated blood, $P L N D$ pelvic lymph node dissection, LVI lymphovascular invasion

$3.615 ; p<0.001)$ were independent predictors of RFS. Similarly, $\mathrm{pT} \geq 3(\mathrm{HR}=5.369 ; p<0.001)$ and $\mathrm{pN}(+)(\mathrm{HR}=$ $3.779 ; p<0.001)$ could predict CSS, while ASA scores $(\mathrm{HR}=2.076 ; p=0.048), \mathrm{pT} \geq 3 \quad(\mathrm{HR}=4.553 ; p<0.001)$, and $\mathrm{pN}(+)(\mathrm{HR}=4.411 ; p<0.001)$ could predict OS independently. The elderly group did not have a significant higher risk of lower RFS (HR=1.096; $p=0.806)$ and CSS (HR= $1.455 ; p=0.337$ ) compared with the younger group after RARC.

\section{Discussion}

The treatment of bladder cancer in elderly patients is still a controversial issue for urologists. Although many reports recommended RC as a therapeutic option for octogenarians $[14,20,21]$. More potential anesthesia risks, more comorbid conditions, and shortened life expectancy in elderly patients often drive physicians and patients away from cystectomy [22-24].

With the development of minimally invasive surgery, especially robot-assisted surgery, the perioperative outcomes, including estimated blood loss (EBL), blood transfusion rates, and rehabilitation, have been improved without sacrificing the oncologic results $[13,25]$. In our cohort, the whole cohort also had a lower EBL than that in the previous open RC cohort [25]. Those suggest that RARC may bring better benefits to the elderly in the respect of intraoperative damage control and enhance the safety of operation relatively. Furthermore, compared with younger group $(n=133)$, Groote et al. found that elderly group $(n=22)$ had similar EBL and significantly shorter operative time [20]. Our study found similar results, but we also suggested that the elderly group had higher blood transfusion rate. It may attribute to the 
Table 2 Logistic regression analysis of high-grade and any grade complications

\begin{tabular}{|c|c|c|c|c|c|c|}
\hline & \multicolumn{3}{|c|}{ Univariable analysis } & \multicolumn{3}{|c|}{ Multivariable analysis } \\
\hline & OR & $95 \% \mathrm{Cl}$ & p-value & OR & $95 \% \mathrm{Cl}$ & p-value \\
\hline \multicolumn{7}{|l|}{ High-grade complications } \\
\hline Age $(\geqq 80$ vs $<80)$ & 1.560 & $0.465-5.234$ & 0.471 & 1.648 & $0.403-6.734$ & 0.487 \\
\hline Sex (male vs female) & 0.332 & $0.096-1.147$ & 0.081 & 0.268 & $0.061-1.182$ & 0.082 \\
\hline PLND (yes vs no) & 0.682 & $0.142-3.267$ & 0.632 & 1.193 & $0.165-8.648$ & 0.861 \\
\hline ASA score(>2 vs $\leq 2)$ & 1.875 & $0.607-5.796$ & 0.275 & 4.662 & $1.036-20.968$ & 0.045 \\
\hline $\mathrm{CCl}$ (continuous variable) & 0.754 & $0.372-1.527$ & 0.433 & 0.463 & $0.168-1.279$ & 0.138 \\
\hline $\mathrm{EBL}, \mathrm{ml}(>500 \mathrm{ml} \mathrm{vs} \leq 500 \mathrm{ml})$ & 0.975 & $0.294-3.238$ & 0.968 & 0.672 & $0.138-3.283$ & 0.623 \\
\hline Transfusion (yes vs no) & 0.838 & $0.253-2.776$ & 0.773 & 0.936 & $0.206-4.250$ & 0.932 \\
\hline Urinary diversion & & & 0.477 & & & 0.354 \\
\hline Ileal conduit vs ureterostomy & 2.043 & $0.608-6.868$ & 0.248 & 2.121 & $0.600-7.501$ & 0.243 \\
\hline Ileal conduit vs neobladder & 2.472 & $0.249-24.561$ & 0.440 & 4.881 & $0.366-65.026$ & 0.230 \\
\hline \multicolumn{7}{|l|}{ Any grade complications } \\
\hline Age $(\geqq 80$ vs $<80)$ & 0.849 & $0.437-1.652$ & 0.630 & 0.831 & $0.395-1.748$ & 0.626 \\
\hline Sex (male vs female) & 0.680 & $0.299-1.545$ & 0.357 & 1.957 & $0.804-4.764$ & 0.139 \\
\hline PLND (yes vs no) & 0.851 & $0.351-2.066$ & 0.722 & 0.953 & $0.341-2.664$ & 0.928 \\
\hline ASA score(>2 vs $\leq 2)$ & 1.210 & $0.704-2.080$ & 0.490 & 0.872 & $0.438-1.737$ & 0.698 \\
\hline CCl (continuous variable) & 1.413 & $0.998-2.000$ & 0.052 & 1.608 & $1.035-2.497$ & 0.035 \\
\hline $\mathrm{EBL}, \mathrm{ml}(>500 \mathrm{ml} \mathrm{vs} \leq 500 \mathrm{ml})$ & 0.752 & $0.414-1.367$ & 0.349 & 0.706 & $0.343-1.456$ & 0.346 \\
\hline Transfusion (yes vs no) & 0.840 & $0.470-1.503$ & 0.557 & 0.831 & $0.407-1.700$ & 0.613 \\
\hline Urinary diversion & & & 0.813 & & & 0.556 \\
\hline Ileal conduit vs ureterostomy & 1.081 & $0.620-1.884$ & 0.784 & 1.075 & $0.600-1.927$ & 0.807 \\
\hline Ileal conduit vs neobladder & 1.533 & $0.406-5.788$ & 0.529 & 2.184 & $0.532-8.975$ & 0.279 \\
\hline
\end{tabular}

lower preoperative hemoglobin in the elderly group than in the younger group. The concerns about elderly patient frailty and relatively poor compensatory ability after blood loss may lead anesthesiologists to relax blood transfusion indications during operation, though perioperative blood transfusion was associated with increased risks of cancer recurrence and mortality following RC [26]. Meanwhile, excessively long operation time may not only alter cognition and reduced recoverability in the elderly, but may also affect cardiovascular,

Table 3 Impact of age ( $\geq 80$ vs $<80$ ) on the blood loss, transfusion, length of stay, high-grade complications, and any grade complications

\begin{tabular}{llll}
\hline & OR & $\mathbf{9 5 \% ~ C l}$ & p-value \\
\hline Blood loss $>500 \mathrm{~mL}$ & 1.149 & $0.499-2.645$ & 0.744 \\
Transfusion & 1.782 & $0.808-3.931$ & 0.152 \\
Length of stay $>18$ days & 0.830 & $0.316-2.177$ & 0.704 \\
High-grade complications & 1.791 & $0.441-7.270$ & 0.415 \\
Any grade complications & 0.834 & $0.396-1.756$ & 0.632 \\
\hline
\end{tabular}

Model adjusted for sex, ASA score, $\mathrm{CCl}$, T stage, $\mathrm{N}$ stage, use of PLND, and diversion technique respiratory, and digestive system, which make surgeons tend to operate faster to reduce anesthetic risks in elderly patients [27]. Therefore, previous studies have shown that ileal conduit, ileal neobladder, and lymphadenectomy was less performed in elderly patients than in the young patients [28-30]. In addition, it was reported that cutaneous ureterostomy can be a suitable alternative to ileal conduit for elderly patients with relevant comorbidities reducing perioperative complications without a negative impact on quality of life (QoL) [31]. In our study, there was a significant difference in the way of urinary diversion between the elderly group and the younger group. Concerned about the risk of anesthesia and the impact on the intestines, the surgeon was more likely to choose ureterostomy in the elderly group, which may lead to shorter operation time in the elderly group.

$\mathrm{RC}$ and urinary diversion present challenges of complications to all the patients, especially to the elderly. A comparative study of RC with different approaches for patients over 75 years suggested that there were no significant differences in surgical morbidity or 90-day readmission rates between the RARC and open RC groups, but RARC was correlated with a shorter hospital 

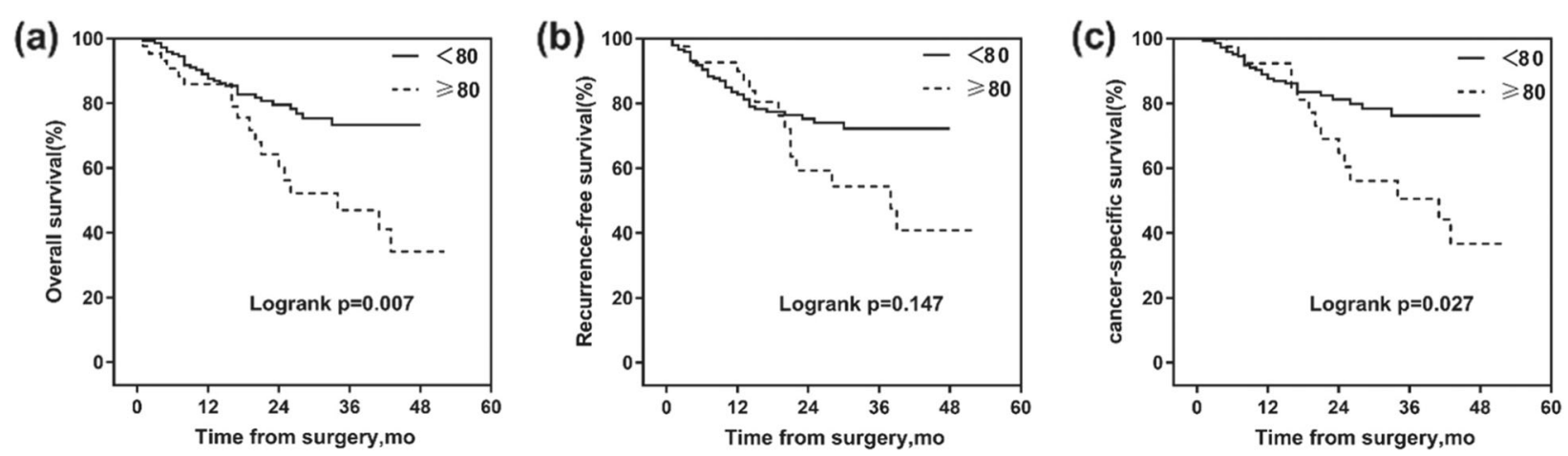

Fig. 1 Kaplan-Meier curves for a overall survival, b recurrence-free survival, and c cancer-specific survival estimates, stratified according to age (mo, months)

Table 4 Cox proportional hazards regression analysis of overall survival, recurrence-free survival, and cancer-specific survival

\begin{tabular}{|c|c|c|c|c|c|c|}
\hline & \multicolumn{3}{|c|}{ Univariable analysis } & \multicolumn{3}{|c|}{ Multivariable analysis } \\
\hline & HR & $95 \% \mathrm{Cl}$ & p-value & HR & $95 \% \mathrm{Cl}$ & $p$-value \\
\hline \multicolumn{7}{|c|}{ Overall survival } \\
\hline Age $(\geqq 80$ vs $<80)$ & 2.564 & $1.465-4.489$ & 0.001 & 1.736 & $0.875-3.442$ & 0.115 \\
\hline Sex male (male vs female) & 0.517 & $0.266-1.005$ & 0.052 & 0.524 & $0.262-1.048$ & 0.067 \\
\hline PLND (yes vs no) & 0.451 & $0.231-0.882$ & 0.020 & 0.501 & $0.207-1.214$ & 0.126 \\
\hline ASA score (>2 vs $\leq 2)$ & 1.889 & $1.080-3.302$ & 0.026 & 2.076 & $1.008-4.276$ & 0.048 \\
\hline CCI (continuous variable) & 1.523 & $1.108-2.093$ & 0.009 & 1.113 & $0.736-1.682$ & 0.613 \\
\hline $\mathrm{pT}(\geqq \mathrm{pT} 3$ vs<pT3) & 6.417 & $3.473-11.855$ & $<0.001$ & 4.553 & $2.359-8.788$ & $<0.001$ \\
\hline $\mathrm{pN}(+\mathrm{vs}-)$ & 4.605 & $2.668-7.950$ & $<0.001$ & 4.411 & $2.322-8.378$ & $<0.001$ \\
\hline Positive surgical margin (+ vs -) & 1.083 & $0.337-3.478$ & 0.893 & 0.520 & $0.148-1.823$ & 0.307 \\
\hline \multicolumn{7}{|c|}{ Recurrence-free survival } \\
\hline Age $(\geqq 80$ vs $<80)$ & 1.665 & $0.921-3.011$ & 0.092 & 1.096 & $0.528-2.271$ & 0.806 \\
\hline Sex male (male vs female) & 0.724 & $0.355-1.477$ & 0.374 & 1.275 & $0.631-2.656$ & 0.515 \\
\hline PLND (yes vs no) & 0.584 & $0.286-1.195$ & 0.141 & 0.572 & $0.232-1.413$ & 0.226 \\
\hline ASA score (>2 vs $\leq 2)$ & 1.354 & $0.798-2.299$ & 0.262 & 0.931 & $0.475-1.826$ & 0.836 \\
\hline CCI (continuous variable) & 1.726 & $1.264-2.358$ & 0.001 & 1.812 & $1.218-2.695$ & 0.003 \\
\hline pT ( $\geqq$ pT3 vs<pT3) & 4.644 & $2.665-8.094$ & $<0.001$ & 3.206 & $1.738-5.913$ & $<0.001$ \\
\hline $\mathrm{pN}(+\mathrm{vs}-)$ & 4.037 & $2.359-6.908$ & $<0.001$ & 3.615 & $1.934-6.755$ & $<0.001$ \\
\hline Positive surgical margin (+ vs -) & 0.670 & $0.163-2.752$ & 0.579 & 0.292 & $0.066-1.288$ & 0.104 \\
\hline \multicolumn{7}{|c|}{ Cancer-specific survival } \\
\hline Age $(\geqq 80$ vs $<80)$ & 2.234 & $1.208-4.132$ & 0.010 & 1.455 & $0.676-3.132$ & 0.337 \\
\hline Sex male (male vs female) & 0.554 & $0.267-1.147$ & 0.112 & 1.690 & $0.795-3.593$ & 0.173 \\
\hline PLND (yes vs no) & 0.492 & $0.235-1.027$ & 0.059 & 0.557 & $0.211-1.476$ & 0.239 \\
\hline ASA score (>2 vs $\leq 2$ ) & 1.656 & $0.920-2.983$ & 0.093 & 1.598 & $0.747-3.417$ & 0.227 \\
\hline CCI (continuous variable) & 1.607 & $1.143-2.261$ & 0.006 & 1.328 & $0.855-2.064$ & 0.206 \\
\hline pT $(\geqq$ pT3 vs<pT3) & 7.471 & $3.781-14.760$ & $<0.001$ & 5.369 & $2.598-11.097$ & $<0.001$ \\
\hline $\mathrm{pN}(+\mathrm{vs}-)$ & 4.364 & $2.423-7.857$ & $<0.001$ & 3.779 & $1.910-7.476$ & $<0.001$ \\
\hline Positive surgical margin (+ vs -) & 0.814 & $0.197-3.363$ & 0.776 & 0.361 & $0.080-1.636$ & 0.186 \\
\hline
\end{tabular}


stay [32]. In our cohort, the incidence of postoperative complications in elderly patients was lower than that in the previous open RC cohort of elderly patients [33]. Those may indicate that RARC has relative advantages over open $\mathrm{RC}$ in terms of postoperative rehabilitation of elderly patients. Moreover, in terms of distribution of complications in different grades or 90-day mortality, Groote et al. showed that there was no significant difference between the elderly and younger group, but they did not analyze the influencing factors of complications [20]. Our research has come to a similar conclusion, and further analysis showed that ASA score and CCI, rather than age, could predict major and any grade complications respectively. Previous RARC cohort also showed that high ASA score was an independent predictor of major complications [34]. Therefore, the incidence of complications after RARC is mainly related to the basic physical condition of the patients, but not to the age.

With regard to survival outcomes, Groote et al. has shown that elderly patients had a similar 3-year RFS but worse CSS compared with young patients, and pathological stage was still the main predictors of survival outcomes [20]. In our study, the octogenarians also had a similar 3-year RFS (Fig. 1), and tumor stage and positive lymph node, rather than age, were significant predictors of oncologic outcomes. However, OS and CSS were significantly higher in elderly. Relatively higher tumor stage, less use of PLND, and physical condition may result in poor OS and CSS for the elderly. Firstly, we have already pointed out that high tumor stage was associated with survival outcomes. Secondly, Chamie et al. suggested that the survival benefit of RC in the elderly is mainly acquired by the use of PLND [35], and Wang et al. pointed out that extended PLND is associated with favorable RFS and disease-specific survival for patients [36]. In our study, although the PLND ratio of the elderly patients $(75 \%)$ was higher than that of the previous elderly cohorts $(32 \%)[20,37]$, it was still lower than that of the younger patients (89\%). This may be due to multidisciplinary discussions among urologists and anesthesiologists, as well as concerns about postoperative complications. Lastly, the impacts of ASA score and CCI, which can reflect the physical condition of the elderly, on long-term survival outcome are still controversial. Previous study has suggested that CCI is an independent predictor of OS [38], but other study has shown that neither CCI nor ASA could be a predictor of 5-year competing (non-bladder cancer) mortality [39]. In our cohort, Cox multivariable regression analysis show that ASA score and CCI can independently predict OS and RFS, respectively. The differences in the accuracy of cancer information record, follow-up time, and sample size may be the explanation for these different findings [38]. To summarize, age should not be the only consideration for the elderly patients with bladder cancer. Preoperative comprehensive assessment is very important for the operation of elderly patients.

This study possessed several limitations. Firstly, our study was a retrospective study in which the survival data were acquired through follow-up; thus, we may not be able to obtain information such as the exact time of recurrence and death of the patient. Secondly, we will get the functional or quality of life data after cystectomy in the next study, so we can compare the differences between younger and older groups in this important aspect. Moreover, including more elderly patients and prolonging the follow-up time will have more persuasion. Finally, selection bias for RARC may also have influenced our results, which make it possible for only elderly patients with relatively good health condition to undergo RARC.

\section{Conclusions}

Based on the outcomes of our comparative study, elderly patients who received RARC do not show increased perioperative risks compared with young patients. Only $\mathrm{T}$ stage and lymph node status, and not age, were able to predict oncologic outcomes. In addition, ASA score and $\mathrm{CCI}$ also have certain value in predicting postoperative complications and short-term survival outcome. Meanwhile, statistically lower OS and CSS remind us to carefully choose candidates for RARC in elderly patients. All in all, RARC can be used as one of the safe treatment options for bladder cancer in selected elderly patients who are relatively healthy.

\section{Abbreviations}

RC: Radical cystectomy; RARC: Robot-assisted radical cystectomy; OS: Overall survival; RFS: Recurrence-free survival; CSS: Cancer-specific survival;

ASA: American Society of Anesthesiologists; CCl: Charlson comorbidity index; MIBC: Muscle invasive bladder cancer; WHO: World Health Organization; AJCC: American Joint Committee on cancer; HR: Hazard risk; Cls: Confidence intervals; PLND: Pelvic lymph node dissection; EBL: Estimated blood loss; LVI: Lymphovascular invasion

\section{Acknowledgements}

We are grateful to all the patients and doctors contributed to this paper.

\section{Authors' contributions}

Rong Yang and Hongqian Guo were responsible for the conception of the work. Shangxun Xie and Zihan Zhao wrote the manuscript. Baofu Feng and Shiwei Zhang made the tables and figures. Gutian Zhang and Xiaogong Li were responsible for retrieving the medical record of the enrolled patients. All authors finally approved the manuscript version to be published.

\section{Funding}

This research has received research grants from National Natural Science Foundation of China $(81772727,81972388,81772710)$ and Nanjing Health Science and Technology Development Fund (ZKX19011).

Availability of data and materials

The raw data of this paper are available upon reasonable request to the corresponding author. 


\section{Declarations}

\section{Ethics approval and consent to participate}

The study was approved by the Ethics Committee of Nanjing Drum Tower Hospital in accordance with the Declaration of Helsinki.

\section{Consent for publication}

As the present study only collected retrospective clinical data and does not pose a risk to the participants, written informed consent was not required.

\section{Competing interests}

The authors declare that they have no conflict of interest.

Received: 26 January 2021 Accepted: 21 June 2021

Published online: 06 July 2021

\section{References}

1. Bray F, Ferlay J, Soerjomataram I, Siegel RL, Torre LA, Jemal A. Global cancer statistics 2018: GLOBOCAN estimates of incidence and mortality worldwide for 36 cancers in 185 countries. CA: a cancer journal for clinicians. 2018; 68(6):394-424. https://doi.org/10.3322/caac.21492.

2. Howlader N NA, Krapcho M, Miller D, Brest A, Yu M, Ruhl J, Tatalovich Z, Mariotto A, Lewis DR, Chen HS, Feuer EJ, Cronin KA (eds) (2020) SEER Cancer Statistics Review, 1975-2017, National Cancer Institute. Bethesda, MD. doi:https://seer.cancer.gov/csr/1975_2017/, based on November 2019 SEER data submission, posted to the SEER web site, April 2020.

3. Flaig TW, Spiess PE, Agarwal N, Bangs R, Boorjian SA, Buyyounouski MK, et al. Bladder cancer, Version 3.2020, NCCN Clinical Practice Guidelines in Oncology. Journal of the National Comprehensive Cancer Network : JNCCN. 2020;18(3):329-54. https://doi.org/10.6004/jnccn.2020.0011.

4. Zhou Y, Zhang ZL, Luo MH, Yang $\mathrm{H}$. Transurethral needle electrode resection and transurethral holmium laser resection of bladder cancer World journal of surgical oncology. 2020;18(1):166. https://doi.org/10.1186/ s12957-020-01943-3

5. Extermann M, Aapro M, Bernabei R, Cohen HJ, Droz J-P, Lichtman S, Mor V, Monfardini S, Repetto L, Sørbye L (2005) Use of comprehensive geriatric assessment in older cancer patients: Recommendations from the task force on CGA of the International Society of Geriatric Oncology (SIOG). Critical reviews in oncology/hematology 55 (3):241-252. doi:https://doi.org/10.1016/ j.critrevonc.2005.06.003

6. Wu B, Pan C, Yao Z, Zhu X, Bai S. A new ureteroileal anastomosis technique in modified ileal orthotopic bladder substitution after radical cystectomy. World journal of surgical oncology. 2020;18(1):72. https://doi.org/10.1186/ s12957-020-01831-w.

7. Tong S, Yang Z, Zu X, Li Y, He W, Li Y, et al. Anterior versus posterior approach laparoscopic radical cystectomy: a retrospective analysis. World journal of surgical oncology. 2019;17(1):9. https://doi.org/10.1186/s12957-01 8-1547-7.

8. Zheng D, Liu J, Wu G, Yang S, Luo C, Du T, et al. Comparison of open and intracorporeal modified ureterosigmoidostomy (Mainz II) after laparoscopic radical cystectomy with bladder cancer. World journal of surgical oncology. 2021;19(1):57. https://doi.org/10.1186/s12957-021-02148-y.

9. Tang K, Li H, Xia D, Hu Z, Zhuang Q, Liu J, et al. Laparoscopic versus open radical cystectomy in bladder cancer: a systematic review and meta-analysis of comparative studies. PloS one. 2014;9(5):e95667. https://doi.org/10.1371/ journal.pone.0095667.

10. Rai BP, Bondad J, Vasdev N, Adshead J, Lane T, Ahmed K, Khan MS, Dasgupta P, Guru K, Chlosta PL, Aboumarzouk OM (2019) Robotic versus open radical cystectomy for bladder cancer in adults. The Cochrane database of systematic reviews 4 (4):Cd011903

11. Bochner BH, Dalbagni G, Sjoberg DD, Silberstein J, Keren Paz GE, Donat SM, et al. Comparing Open Radical Cystectomy and Robot-assisted Laparoscopic Radical Cystectomy: A Randomized Clinical Trial. Eur Urol. 2015;67(6):104250. https://doi.org/10.1016/j.eururo.2014.11.043.

12. Tyritzis SI, Collins J, Wiklund NP. The current status of robot-assisted cystectomy. Indian Journal of Urology. 2018;34(2):101-9. https://doi.org/1 0.4103/iju.IJU_355_17.

13. Bochner BH, Dalbagni G, Marzouk KH, Sjoberg DD, Lee J, Donat SM, et al. Randomized trial comparing open radical cystectomy and robot-assisted laparoscopic radical cystectomy: oncologic outcomes. European urology. 2018;74(4):465-71. https://doi.org/10.1016/j.eururo.2018.04.030.
14. Phillips EA, Uberoi V, Tuerk IA. Robot-assisted radical cystectomy in octogenarians. Journal of endourology. 2014;28(2):219-23. https://doi.org/1 0.1089/end.2013.0159

15. Lau CS, Talug J, Williams SB, Josephson DY, Ruel NH, Chan KG, et al. Robotic-assisted laparoscopic radical cystectomy in the octogenarian. The International Journal of Medical Robotics and Computer Assisted Surgery. 2012;8(2):247-52. https://doi.org/10.1002/rcs.460.

16. Humphrey PA, Moch H, Cubilla AL, Ulbright TM, Reuter VE. The 2016 WHO classification of tumours of the urinary system and male genital organs_-part B: prostate and bladder tumours. European urology. 2016; 70(1):106-19. https://doi.org/10.1016/j.eururo.2016.02.028.

17. AminMB E, GreeneF,etal,eds (2017) AJCC Cancer Staging Manual. 8th ed. Springer. doi:https://doi.org/10.1007/978-3-319-40618-3

18. Dindo D, Demartines N, Clavien P. Classification of surgical complications: a new proposal with evaluation in a cohort of 6336 patients and results of a survey. Ann Surg. 2004;240(2):205-13. https://doi.org/10.1097/01.sla.0000133 083.54934.ae.

19. Peduzzi P, Concato J, Kemper E, Holford TR, Feinstein AR. A simulation study of the number of events per variable in logistic regression analysis. Journal of clinical epidemiology. 1996;49(12):1373-9. https://doi.org/10.1016/ s0895-4356(96)00236-3.

20. De Groote R, Gandaglia G, Geurts N, Goossens M, Pauwels E, D'Hondt F, et al. Robot-assisted radical cystectomy for bladder cancer in octogenarians. Journal of endourology. 2016;30(7):792-8. https://doi.org/10.1089/end.2016. 0050.

21. Yanagihara Y, Nishida K, Watanabe R, Koyama K, Sawada Y, Noda T, et al. Feasibility of laparoscopic radical cystectomy in elderly patients: a comparative analysis of clinical outcomes in a single institution. Acta Medica Okayama. 2019;73(5):417-8.

22. Prout GR Jr, Wesley MN, Yancik R, Ries LA, Havlik RJ, Edwards BK. Age and comorbidity impact surgical therapy in older bladder carcinoma patients: a population-based study. Cancer. 2005;104(8):1638-47. https://doi.org/10.1 002/cncr.21354.

23. Izquierdo L, Peri L, Leon P, Ramírez-Backhaus M, Manning T, Alcaraz A, et al. The role of cystectomy in elderly patients-a multicentre analysis. BJU international. 2015:116:73-9. https://doi.org/10.1111/bju.13227.

24. Shariat SF, Milowsky M, Droller MJ. Bladder cancer in the elderly. Urologic Oncology Seminars \& Original Investigations. 2009;27(6):653-67. https://doi. org/10.1016/j.urolonc.2009.07.020

25. Bochner BH, Dalbagni G, Sjoberg DD, Silberstein J, Paz GEK, Donat SM, et al. Comparing open radical cystectomy and robot-assisted laparoscopic radical cystectomy: a randomized clinical trial. European urology. 2015;67(6):104250. https://doi.org/10.1016/j.eururo.2014.11.043.

26. Linder BJ, Frank I, Cheville JC, Tollefson MK, Thompson RH, Tarrell RF, et al. The impact of perioperative blood transfusion on cancer recurrence and survival following radical cystectomy. European urology. 2013;63(5):839-45. https://doi.org/10.1016/j.eururo.2013.01.004.

27. Shariat SF, Milowsky M, Droller MJ. Bladder cancer in the elderly. Urologic oncology. 2009;27(6):653-67. https://doi.org/10.1016/j.urolonc.2 009.07.020.

28. Garde H, Ciappara M, Galante I, Fuentes Ferrer M, Gómez A, Blazquez J, et al. Radical cystectomy in octogenarian patients: a difficult decision to take. Urol Int. 2015:94(4):390-3. https://doi.org/10.1159/000371556.

29. Stroumbakis N, Herr HW, Cookson MS, Fair WR. Radical cystectomy in the octogenarian. J Urol. 1997;158(6):2113-7. https://doi.org/10.1016/s0022-534 7(01)68171-0

30. Stein JP, Lieskovsky G, Cote R, Groshen S, Feng AC, Boyd S, et al. Radical cystectomy in the treatment of invasive bladder cancer: long-term results in 1,054 patients. Journal of clinical oncology : official journal of the American Society of Clinical Oncology. 2001;19(3):666-75. https://doi.org/10.1200/jco.2 001.19.3.666.

31. Longo N, Imbimbo C, Fusco F, Ficarra V, Mangiapia F, Di Lorenzo G, et al. Complications and quality of life in elderly patients with several comorbidities undergoing cutaneous ureterostomy with single stoma or ileal conduit after radical cystectomy. BJU Int. 2016;118(4):521-6. https://doi. org/10.1111/bju.13462.

32. Nguyen DP, Awamlh BAHA, Charles Osterberg E, Chrystal J, Flynn T, Lee DJ, et al. Postoperative complications and short-term oncological outcomes of patients aged $\geq 80$ years undergoing robot-assisted radical cystectomy. World Journal of Urology. 2015;33(9):1315-21. https://doi.org/10.1007/s0034 5-014-1446-7. 
33. Donat SM, Siegrist T, Cronin A, Savage C, Milowsky MI, Herr HW. Radical cystectomy in octogenarians-does morbidity outweigh the potential survival benefits? The Journal of urology. 2010;183(6):2171-7. https://doi. org/10.1016/j.juro.2010.02.015.

34. Smith $A B$, Raynor M, Amling CL, Busby JE, Castle E, Davis R, et al. Multiinstitutional analysis of robotic radical cystectomy for bladder cancer: perioperative outcomes and complications in 227 patients. Journal of Laparoendoscopic \& Advanced Surgical Techniques. 2012;22(1):17-21. https://doi.org/10.1089/lap.2011.0326.

35. Chamie K, Hu B, DeVere White RW, Ellison LM. Cystectomy in the elderly: does the survival benefit in younger patients translate to the octogenarians? BJU international. 2008;102(3):284-90. https://doi.org/1 0.1111/j.1464-410X.2008.07636.x.

36. Wang YC, Wu J, Dai B, Shen YJ, Ma CG, Ye DW, et al. Extended versus nonextended lymphadenectomy during radical cystectomy for patients with bladder cancer: a meta-analysis of the effect on long-term and short-term outcomes. World journal of surgical oncology. 2019;17(1):225. https://doi. org/10.1186/s12957-019-1759-5.

37. Zattoni F, Palumbo V, Giannarini G, Crestani A, Kungulli A, Novara G, et al. Perioperative outcomes and early survival in octogenarians who underwent radical cystectomy for bladder cancer. Urologia internationalis. 2018;100(1): 13-7. https://doi.org/10.1159/000478990.

38. Fischer-Valuck BW, Rao YJ, Rudra S, Przybysz D, Germino E, Samson P, et al. Treatment patterns and overall survival outcomes of octogenarians with muscle invasive cancer of the bladder: an analysis of the national cancer database. The Journal of urology. 2018;199(2):416-23. https://doi.org/10.101 6/j.juro.2017.08.086.

39. Froehner M, Koch R, Hübler M, Heberling U, Novotny V, Zastrow S, et al. Predicting 90-day and long-term mortality in octogenarians undergoing radical cystectomy. BMC urology. 2018;18(1):91. https://doi.org/10.1186/s12 894-018-0402-z

\section{Publisher's Note}

Springer Nature remains neutral with regard to jurisdictional claims in published maps and institutional affiliations.

Ready to submit your research? Choose BMC and benefit from:

- fast, convenient online submission

- thorough peer review by experienced researchers in your field

- rapid publication on acceptance

- support for research data, including large and complex data types

- gold Open Access which fosters wider collaboration and increased citations

- maximum visibility for your research: over $100 \mathrm{M}$ website views per year

At $\mathrm{BMC}$, research is always in progress.

Learn more biomedcentral.com/submissions 